\title{
Biophysical Investigation of Sodium Channel Interaction with $\beta$-Subunit Variants Associated with Arrhythmias
}

\author{
José P. Llongueras, MSc, ${ }^{1, *}$ Samir Das, MSc, PhD, ${ }^{2,3,{ }^{*}}$ Jolien De Waele, MSc, ${ }^{4}$ Lucio Capulzini, MD, ${ }^{5}$ \\ Antonio Sorgente, MD, PhD, FHRS, ${ }^{5}$ Filip Van Petegem, MSc, PhD, ${ }^{2,3}$ and Frank Bosmans, MPharm, PhD $^{4}$
}

\begin{abstract}
Background: Voltage-gated sodium $\left(\mathrm{Na}_{\mathrm{V}}\right)$ channels help regulate electrical activity of the plasma membrane. Mutations in associated subunits can result in pathological outcomes. Here we examined the interaction of $\mathrm{Na}_{\mathrm{V}}$ channels with cardiac arrhythmia-linked mutations in $S C N 2 B$ and $S C N 4 B$, two genes that encode auxiliary $\beta$-subunits.

Materials and Methods: To investigate changes in $S C N 2 B^{\mathrm{R} 137 \mathrm{H}}$ and $S C N 4 B^{\mathrm{I} 80 \mathrm{~T}}$ function, we combined threedimensional X-ray crystallography with electrophysiological measurements on $\mathrm{Na}_{\mathrm{V}} 1.5$, the dominant subtype in the heart.

Results: $S C N 4 B^{\mathrm{I} 80 \mathrm{~T}}$ alters channel activity, whereas $S C N 2 B^{\mathrm{R} 137 \mathrm{H}}$ does not have an apparent effect. Structurally, the $S C N 4 B^{\mathrm{I} 80 \mathrm{~T}}$ perturbation alters hydrophobic packing of the subunit with major structural changes and causes a thermal destabilization of the folding. In contrast, $S C N 2 B^{\mathrm{R} 137 \mathrm{H}}$ leads to structural changes but overall protein stability is unaffected.

Conclusion: $S C N 4 B^{180 \mathrm{~T}}$ data suggest a functionally important region in the interaction between $\mathrm{Na}_{\mathrm{V}} 1.5$ and $\beta 4$ that, when disrupted, could lead to channel dysfunction. A lack of apparent functional effects of $S C N 2 B^{\mathrm{R} 137 \mathrm{H}}$ on $\mathrm{Na}_{\mathrm{V}} 1.5$ suggests an alternative working mechanism, possibly through other $\mathrm{Na}_{\mathrm{V}}$ channel subtypes present in heart tissue. Indeed, mapping the structural variations of $S C N 2 B^{\mathrm{R} 137 \mathrm{H}}$ onto neuronal $\mathrm{Na}_{\mathrm{V}}$ channel structures suggests altered interaction patterns.
\end{abstract}

Keywords: $\mathrm{Na}_{\mathrm{V}} 1.5$, arrhythmia, $S C N 2 B, S C N 4 B$

\section{Introduction}

V OLTAGE-GATED SODIUM $\left(\mathrm{Na}_{\mathrm{V}}\right)$ channel mutations can cause dramatic alterations in cellular excitability leading to potentially life-threatening disorders. ${ }^{1}{ }^{\text {In }}$ cardiac myocytes, $\mathrm{Na}_{\mathrm{V}} 1.5$ is the main $\mathrm{Na}_{\mathrm{V}}$ channel subtype responsible for heart muscle function. ${ }^{2,3}$ Consequently, mutations in this channel have indeed been associated with long QT syndrome (LQTS) ${ }^{4}$ and Brugada syndrome (BrS). ${ }^{5}$ However, it is now well established that $\mathrm{Na}_{\mathrm{V}}$ channels do not function in isolation but form membrane-embedded macromolecular complexes that include auxiliary proteins such as $\beta$-subunits, ${ }^{1,6-8}$ fibroblast growth factor proteins, calmodulin, and others. ${ }^{9-16} \beta$-subunits are known to modify gating properties, regulate trafficking, and influence plasma membrane recruitment of $\mathrm{Na}_{\mathrm{V}}$ channels. ${ }^{6}$ Four main $\beta$-subunit isoforms ( $\beta 1-4)$ have been identified and despite a shared, single transmembrane-segment protein topology, each interacts distinctly with and exerts disparate effects on specific $\mathrm{Na}_{\mathrm{V}}$ channel subtypes $\left(\mathrm{Na}_{\mathrm{V}} 1.1-1.9\right){ }^{6,17-19}$ All four $\beta$-subunits have been identified in atrial and ventricular cardiomyocytes, ${ }^{2}$ and mutations have been implicated in cardiac disorders. ${ }^{20}$

Potential disease-associated mutations have also been found in $S C N 4 B$ (p.Ile80Thr) and $S C N 2 B$ (p.Arg137His), encoding the $\mathrm{Na}_{\mathrm{V}}$ channel $\beta 4$ - and $\beta 2$-subunit, respectively. ${ }^{1,21}$ These mutations were identified during genetic screening in two patients affected by familial atrial fibrillation and LQTS, respectively (www.ncbi.nlm.nih.gov/clinvar/). In this study, we investigated the functional and structural consequences of these mutations on $\mathrm{Na}_{\mathrm{V}}$ channel complex function, providing initial evidence of altered interactions.

\section{Methods}

\section{Electrophysiological recordings in Xenopus} laevis oocytes

DNA sequencing of human (h) $\mathrm{Na}_{\mathrm{V}} 1.2, \mathrm{hNa}_{\mathrm{V}} 1.5 \mathrm{C} 373 \mathrm{Y}$, $\mathrm{h} \beta 2$, and $\mathrm{h} \beta 4$ (Origene, USA) was confirmed by automated Sanger sequencing. ${ }^{22} \beta$-subunit mutants were generated

\footnotetext{
${ }^{1}$ Department of Physiology, Johns Hopkins University School of Medicine, Baltimore, Maryland, USA.

${ }^{2}$ Department of Biochemistry and Molecular Biology, University of British Columbia, Vancouver, Canada.

${ }^{3}$ Life Sciences Institute, University of British Columbia, Vancouver, Canada.

${ }_{5}^{4}$ Department of Basic and Applied Medical Sciences, Ghent University, Ghent, Belgium.

${ }^{5}$ Arrhythmia and Electrophysiology Center, Department of Cardiology, Epicura Hospitalier Center, Hornu, Belgium.

*Both authors contributed equally to this work.
} 
Table 1. Gating Parameters of Nav Channels Without and in the Presence of $\beta$-Subunits and Mutants

\begin{tabular}{|c|c|c|c|c|c|c|c|c|c|c|}
\hline & \multicolumn{5}{|c|}{ Activation } & \multicolumn{5}{|c|}{ Channel availability } \\
\hline & $\mathrm{N}$ & $\mathrm{V}_{1 / 2}$ & $S E M$ & $\mathrm{~d}(\mathrm{x})$ & SEM & $\mathrm{N}$ & $\mathrm{V}_{1 / 2}$ & $S E M$ & $d(x)$ & SEM \\
\hline $\mathrm{Na}_{V} 1.5$ & 7 & -39.8 & 0.1 & 4.6 & 0.1 & 5 & -73.8 & 0.5 & 8.0 & 0.3 \\
\hline$\beta 4$ & 6 & $-35.6^{\mathrm{a}}$ & 0.2 & $5.7^{\mathrm{a}}$ & 0.1 & 6 & -74.4 & 0.5 & $9.6^{\mathrm{a}}$ & 0.3 \\
\hline I80T & 5 & $-40.1^{\mathrm{b}}$ & 0.2 & $4.8^{\mathrm{b}}$ & 0.2 & 5 & $-78.5^{\mathrm{a}, \mathrm{b}}$ & 0.5 & 8.9 & 0.2 \\
\hline$\beta 2$ & 5 & $-34.7^{\mathrm{a}}$ & 0.3 & $6.5^{\mathrm{a}}$ & 0.3 & 7 & $-67.2^{\mathrm{a}}$ & 0.4 & 7.9 & 0.2 \\
\hline $\mathrm{R} 137 \mathrm{H}$ & 5 & $-35.3^{\mathrm{a}}$ & 0.5 & $7.0^{\mathrm{a}}$ & 0.5 & 5 & $-68.7^{\mathrm{a}}$ & 0.5 & 7.8 & 0.3 \\
\hline $\mathrm{Na}_{\mathrm{V}} 1.1$ & 6 & -20.5 & 0.2 & 6.3 & 0.2 & 5 & -32.3 & 0.4 & 7.6 & 0.3 \\
\hline$\beta 4$ & 5 & -22.1 & 0.1 & 5.7 & 0.1 & 6 & -31.4 & 0.2 & 7.3 & 0.3 \\
\hline $\mathrm{I} 80 \mathrm{~T}$ & 4 & -20.6 & 0.2 & 6.3 & 0.1 & 6 & -31.8 & 0.2 & 7.7 & 0.1 \\
\hline $\mathrm{Na}_{\mathrm{V}} 1.2$ & 5 & -22.5 & 0.3 & 5.4 & 0.3 & 5 & -37.7 & 0.4 & 9.00 & 0.4 \\
\hline$\beta 4$ & 5 & -21.9 & 0.4 & 5.1 & 0.4 & 5 & -34.9 & 0.3 & $7.1^{\mathrm{a}}$ & 0.3 \\
\hline $\mathrm{I} 80 \mathrm{~T}$ & 5 & -21.9 & 0.3 & 6.0 & 0.2 & 4 & -35.6 & 0.3 & $9.1^{\mathrm{b}}$ & 0.2 \\
\hline$\beta 2$ & 5 & $-18.8^{\mathrm{a}}$ & 0.4 & 4.5 & 0.4 & 5 & $-34.9^{\mathrm{a}}$ & 0.4 & 9.3 & 0.4 \\
\hline $\mathrm{R} 137 \mathrm{H}$ & 5 & $-22.0^{\mathrm{b}}$ & 0.6 & 4.9 & 0.5 & 5 & -36.0 & 0.6 & 9.4 & 0.6 \\
\hline
\end{tabular}

$N=$ number of experiments, $d(x)=$ slope value.

${ }_{1}^{\mathrm{a}} p<0.01$ compared with WT channel by unpaired $t$-test.

${ }^{\mathrm{b}} p<0.01$ compared with WT $\beta$-subunit by unpaired $t$-test.

SEM, standard error of the mean; WT, Wild-Type.

using the Gibson assembly method. cRNA was synthesized using T7 polymerase (the mMessage mMachine Kit; Life Technologies, USA) after linearizing the DNA by restriction enzyme digest. $\mathrm{hNa}_{\mathrm{V}}$ channel constructs were expressed in Xenopus laevis oocytes (sourced from Xenopus one ${ }^{\circledR}$ ) with or without a $\beta$-subunit (1:5 molar ratio) and electrophysiological recordings were taken 2-4 days post cRNA injection. Oocytes were maintained at $17^{\circ} \mathrm{C}$ in Barth's medium $(96 \mathrm{mM}$ $\mathrm{NaCl}, 2 \mathrm{mM} \mathrm{KCl}, 5 \mathrm{mM}$ HEPES, $1 \mathrm{mM} \mathrm{MgCl}$, and $1.8 \mathrm{mM}$ $\mathrm{CaCl}_{2}, 50 \mu \mathrm{g} / \mathrm{mL}$ gentamicin, $\mathrm{pH}$ 7.6) and studied using the two-electrode voltage clamp recording technique (OC-725C; Warner Instruments, USA) with a $150 \mu \mathrm{L}$ recording chamber. All data were filtered at $4 \mathrm{kHz}$ and digitized at $20 \mathrm{kHz}$ using pClamp 10 software (Molecular Devices, USA). The external recording solution used was ND100 $(100 \mathrm{mM} \mathrm{NaCl}, 5 \mathrm{mM}$ HEPES, $1 \mathrm{mM} \mathrm{MgCl} 2$, and $1.8 \mathrm{mM} \mathrm{CaCl}_{2}, \mathrm{pH} 7.6$ ) and microelectrode resistances were $0.5-1.0 \mathrm{M} \Omega$ when filled with $3 \mathrm{M} \mathrm{KCl}$. Recordings were performed at room temperature $\left(\sim 22^{\circ} \mathrm{C}\right)$ and leak and background conductance, identified by blocking $\mathrm{Na}_{\mathrm{V}} 1.2$ and the tetrodotoxin (TTX)-sensitive $\mathrm{Na}_{\mathrm{V}} 1.5 \mathrm{C} 373 \mathrm{Y}$ channel with TTX (Alomone Labs, Israel), was subtracted for all channel currents. Off-line data analysis was performed using Clampfit 10 (Molecular Devices), Excel (Microsoft, USA), and Prism 7 (GraphPad, USA).

\section{Qualitative surface biochemistry}

$X$. laevis oocytes expressing $\mathrm{hNa}_{\mathrm{V}} 1.5, \mathrm{~h} \beta 4, \mathrm{~h} \beta 4-\mathrm{I} 80 \mathrm{~T}, \mathrm{~h} \beta 2$, $\mathrm{h} \beta 2-\mathrm{R} 137 \mathrm{H}$ were washed $2 \times$ with ND100 and incubated with $0.5 \mathrm{mg} / \mathrm{mL}$ Sulfo-NHS-LC-biotin (Pierce, USA) for $1 \mathrm{~h}$ at $4^{\circ} \mathrm{C}$. Oocytes were then washed $6 \times$ in ND100 before lysis by sonication in $20 \mu \mathrm{L} /$ oocyte Nonidet P-40 (NP-40, 1\%) with protease inhibitor cocktail (Pierce). All subsequent steps were performed at $4^{\circ} \mathrm{C}$. Lysates were gently shaken for $15 \mathrm{~min}$ and then centrifuged for $15 \mathrm{~min}$ at $14,000 \mathrm{rpm}$. The pellet was discarded and $40 \mu \mathrm{L}$ of the supernatant was reserved as the total protein fraction. The surface fraction was generated by adding the remaining supernatant to $200 \mu \mathrm{L}$ of MyOne ${ }^{\mathrm{TM}}$ Streptavidin C1 magnetic beads (Invitrogen, USA), raising the volume to $1 \mathrm{~mL}$ with $\mathrm{NP}-40$, and then rotating overnight at $4^{\circ} \mathrm{C}$. Beads were then washed $6 \times$ with NP-40 and resuspended in $30 \mu \mathrm{L} \mathrm{NP}-40$, after which the biotinylated protein was dissociated by addition of $1 \times$ Bolt $^{\mathrm{TM}}$ Sample Buffer plus Reducing Agent (Thermo Fisher Scientific, USA) and boiling at $95^{\circ} \mathrm{C}$ for 5 min. Protein concentrations were measured by bicinchoninic acid assay (Pierce) and samples were run on a Bolt 4-12\% Bis-Tris Plus gel (Thermo Fisher Scientific), then subsequently analyzed by western immunoblotting. Membrane images were cropped to show relevant bands only.

\section{Statistical analyses}

Mean data points for fast inactivation time constants $(\tau)$, persistent current, and recovery from fast inactivation (RFI) were analyzed using a one-way analysis of variance. For data on normalized conductance-voltage and steady-state inactivation relationships presented in Table 1, unpaired Student's $t$-test against wild-type channel or wild-type $\beta$-subunit was used. Values in all cases reflect the mean and error bars reflect standard error of the mean. All analyses were carried out using Excel (Microsoft).

\section{Recombinant protein production and crystallographic analysis}

Human $\beta 4$ C58A (residues 32-157) and $\beta 2$ C55A (residues $30-153)$ were cloned into a modified pET28 vector. ${ }^{17,18}$ The $\beta 4-\mathrm{C} 58 \mathrm{~A} / \mathrm{I} 80 \mathrm{~T}$ and $\beta 2 \mathrm{C} 55 \mathrm{~A} / \mathrm{R} 137 \mathrm{H}$ mutations were introduced using the QuikChange Kit from Agilent Technologies (USA). Both mutants were expressed at $18^{\circ} \mathrm{C}$ in Escherichia coli Rosetta (DE3) pLacI strains (Novagen, USA), induced at an OD600 of $\sim 0.6$ with $0.4 \mathrm{mM} \mathrm{IPTG}$, and grown overnight before harvesting. Cells were lysed through sonication in buffer A (250 mM KCl and $10 \mathrm{mM}$ HEPES at $\mathrm{pH} 7.4)$, supplemented with $25 \mathrm{mg} / \mathrm{mL}$ DNaseI and $25 \mathrm{mg} / \mathrm{mL}$ lysozyme. After centrifugation, the supernatants were applied to a PorosMC column (Tosoh Biosep, USA), washed with buffer A plus $10 \mathrm{mM}$ imidazole, and eluted with buffer B $(250 \mathrm{mM}$ $\mathrm{KCl}$ plus $500 \mathrm{mM}$ imidazole $\mathrm{pH}$ 7.4). 
The mutants were dialyzed overnight against buffer $\mathrm{A}$ and cleaved simultaneously with recombinant tobacco etch virus (TEV) protease. Next, the samples were run on another PorosMC column in buffer A, and the flowthrough was collected and dialyzed against buffer $\mathrm{C}(10 \mathrm{mM} \mathrm{KCl}$ plus $10 \mathrm{HEPES}$ at pH 7.4), applied to a HiloadQ column (GE Healthcare, USA), and eluted with gradients from $0 \%$ to $30 \%$ buffer D $(2 \mathrm{M} \mathrm{KCl}$ plus $10 \mathrm{mM}$ HEPES at $\mathrm{pH}$ 7.4). Finally, samples were run on a Superdex 75 (GE Healthcare) gel filtration column in buffer A. $\beta 4-\mathrm{C} 58 \mathrm{~A} / \mathrm{I} 80 \mathrm{~T}$ and $\beta 2-\mathrm{C} 55 \mathrm{~A} / \mathrm{R} 137 \mathrm{H}$ were exchanged to $50 \mathrm{mM} \mathrm{KCl}$ plus $10 \mathrm{mM}$ HEPES (pH 7.4), concentrated to 9.5 and $2.8 \mathrm{mg} / \mathrm{mL}$, respectively using Amicon concentrator (3K MWCO; Millipore, USA), and stored at $-80^{\circ} \mathrm{C}$.

\section{Crystallization, data collection, and structure solution}

Crystals were grown using the hanging-drop method at $4^{\circ} \mathrm{C}$. $\beta 4-\mathrm{C} 58 \mathrm{~A} / \mathrm{I} 80 \mathrm{~T}$ was crystallized in $0.1 \mathrm{M} \mathrm{MES}(\mathrm{pH} 6.5$ ), $15-17 \%(\mathrm{w} / \mathrm{v})$ PEG 2000-MME and $\beta 2-\mathrm{C} 55 \mathrm{~A} / \mathrm{R} 137 \mathrm{H}$ crystals were grown in 0.1 M HEPES ( $\mathrm{pH} 7.0$ ), 14\% PEG 6000 using seeds from $\beta 2-\mathrm{C} 55 \mathrm{~A}$ crystals at various dilutions. Crystals were flash frozen after transfer to the mother liquor supplemented with $30 \%$ glycerol. The datasets were collected at the beam line BL9-2 of the Stanford Synchrotron Radiation Lightsource and beam line 23-ID-D at the Advanced Photon Source (Chicago). Data were processed using $\mathrm{XDS}^{23}$ and HKL3000. ${ }^{24}$ Phases were obtained through molecular replacement through Phaser $^{25}$ using the available crystal structures of $\beta 4-\mathrm{C} 58 \mathrm{~A}$ (4MZ2.pdb) and $\beta 2-\mathrm{C} 55 \mathrm{~A}$ (5FEB.pdb). The structures were completed by manual model building in $\mathrm{COOT}^{26}$ and refinement using Phenix. ${ }^{27}$ Simulated annealing composite omit maps were calculated with $\mathrm{CNS}^{28}$ software to verify the absence of residual model bias. All structure figures were prepared using PYMOL (DeLano Scientific, San Carlos, USA). Protein Data Bank (PDB) IDs for mutant $\beta$-subunits are 6VRR and 6VSV.

\section{Circular dichroism spectroscopy}

All proteins were diluted to $16 \mu \mathrm{M}$ in $50 \mathrm{mM} \mathrm{KCl}$, $10 \mathrm{mM}$ K-phosphate, $\mathrm{pH} 7.6$ supplemented with $5 \mathrm{mM} \beta$ mercaptoethanol. Spectra were measured from 200$260 \mathrm{~nm}$ in a Jacso J-810. The initial thermal melt of $\beta 4-\mathrm{C} 58 \mathrm{~A}$ from $25^{\circ} \mathrm{C}$ to $95^{\circ} \mathrm{C}$ in a Peltier controlled sample chamber connected to a water bath showed highest secondary structural changes at $213 \mathrm{~nm}$. For all subsequent melts, the signal at $213 \mathrm{~nm}$ was monitored as a function of temperature.

\section{Results}

We examined the effects of $S C N 4 B, S C N 4 B^{\mathrm{I} 80 \mathrm{~T}}\left(\beta 4^{\mathrm{I}}{ }^{\mathrm{I} 0 \mathrm{~T}}\right)$, $S C N 2 B$, and $S C N 2 B^{\mathrm{R} 137 \mathrm{H}}\left(\beta 2^{\mathrm{R} 137 \mathrm{H}}\right)$ on $\mathrm{Na}$ channel gating. These mutations were chosen from the ClinVar database (www.ncbi.nlm.nih.gov/clinvar/), which contains many gene variants of unknown or unsubstantiated clinical significance. In this database, both variants are linked to LQTS 10, a cardiac electrophysiological disorder characterized by QT prolongation and T-wave abnormalities associated with tachyarrhythmias and syncope events that typically occur during exercise or emotional stress. ${ }^{29,30}$ Original data were submitted to ClinVar by Invitae, a genetic testing company based in California (USA). In this study, we exploit this in- formation to investigate possible changes in $\mathrm{SCN} 2 \mathrm{~B}$ and $\mathrm{SCN} 4 \mathrm{~B}$ interaction with $\mathrm{Na}_{\mathrm{V}}$ channels, which may lay the foundation for future experiments in which a link with the clinical phenotype is investigated.

\section{Electrophysiological analysis}

Since the clinical phenotype revolves around heart function, we used human (h) $\mathrm{Na}_{\mathrm{V}} 1.5$ as our model channel. ${ }^{3} \mathrm{Si}$ milar to wild-type $\mathrm{h} \beta 4$ and $\mathrm{h} \beta 2$, both $\mathrm{h} \beta 4^{\mathrm{I}}{ }^{\mathrm{I} 0 \mathrm{~T}}$ and $\mathrm{h} \beta 2^{\mathrm{R} 137 \mathrm{H}}$ express in Xenopus oocytes and translocate to the membrane, indicating that protein trafficking is not affected, at least in a heterologous Xenopus oocyte expression system (Figs. 1 and 2). To discern potential subtle effects of $\mathrm{h} \beta 4$ and $\mathrm{h} \beta 2$ on $\mathrm{Na}_{\mathrm{V}}$ channel function, we recorded and compared multiple gating parameters, such as the conductance-voltage (G-V) relationship, channel availability (I-V), RFI, and persistent current between $\mathrm{hNa}_{\mathrm{V}} 1.5$ alone or in the presence of $\mathrm{h} \beta 4$ or $\mathrm{h} \beta 4^{\mathrm{I} 80 \mathrm{~T}}$. Channel opening kinetics were not studied due to inherent technical limitations associated with electrophysiological recordings in Xenopus oocytes.

We found that the G-V relationship of $h \mathrm{ha}_{\mathrm{V}} 1.5 / \mathrm{h} \beta 4^{\mathrm{I} 80 \mathrm{~T}}$ is shifted to more hyperpolarized potentials $( \pm 5 \mathrm{mV} ; p<0.01)$ when compared with $\mathrm{hNa}_{\mathrm{V}} 1.5 / \mathrm{h} \beta 4$. A similar shift was seen in channel availability $( \pm 4 \mathrm{mV} ; p<0.01)$. Another apparent effect of $\mathrm{h} \beta 4^{\mathrm{I}}{ }^{\mathrm{T} 0 \mathrm{~T}}$ emerged when fitting the current decay phase with a single-exponential fit. Over a 45-mV range, $\mathrm{h} \beta 4^{\mathrm{I} 80 \mathrm{~T}}$ caused $\mathrm{Na}_{\mathrm{V}} 1.5$ currents to inactivate significantly faster when compared with wild-type $\mathrm{h} \beta 4(p<0.05)$. Persistent current and RFI of $\mathrm{hNa}_{\mathrm{V}} 1.5$ were unaffected (Fig. 3). The G-V and I-V relationships of two neuronal $\mathrm{Na}_{\mathrm{V}}$ channel subtypes, $\mathrm{hNa}_{\mathrm{V}} 1.1$ and $\mathrm{hNa}$ 1.2, were not disrupted by the $\mathrm{h} \beta 4^{\mathrm{II0T}}$ mutation (Fig. 3). Markedly, $\mathrm{h} \beta 2^{\mathrm{R} 137 \mathrm{H}}$ did not have any apparent effect on the tested $\mathrm{hNa}_{\mathrm{V}} 1.5$ gating parameters as compared with wild-type $\mathrm{h} \beta 2$ (Fig. 2).

\section{Crystallographic analysis}

Since $\mathrm{h} \beta 2$ and $\mathrm{h} \beta 4$ can be crystallized, ${ }^{17,18}$ we prepared crystals for the $\mathrm{h} \beta 2^{\mathrm{R} 137 \mathrm{H}}$ and $\mathrm{h} \beta 4^{\mathrm{I} 80 \mathrm{~T}}$ variants (PDB IDs are 6VRR and 6VSV). Both resulted in high-resolution structures of 1.45 and $1.65 \AA$, respectively (Table 2). Figure 4 shows a comparison of wild-type and $\mathrm{h} \beta 2^{\mathrm{R} 137 \mathrm{H}}$. The two structures can be superposed with an root-mean-square deviation (RMSD) of $0.79 \AA$ for $90 \mathrm{C} \alpha$ atoms (with $\mathrm{C} \alpha$ atoms of residues with double conformations not included). The R137H mutation results in multiple structural changes at distances $>12 \AA$ away from the mutation site. In wild-type $\mathrm{h} \beta 2$, the $\mathrm{Arg}^{137}$ side chain is stacked against the side chain of Tyr ${ }^{128}$, making cation $-\pi$ interactions. It also forms two hydrogen bonds with a water molecule involved in a hydrogen-bond network, including $\mathrm{Ser}^{64}$ and the $\mathrm{Tyr}^{128}$ main chain. In the $\mathrm{h} \beta 2^{\mathrm{R} 137 \mathrm{H}}$, these interactions are lost, resulting in a reorientation of the Ser $^{64}$ side chain. Instead, His ${ }^{137}$ adopts a dual conformation and a $1.6 \AA$ displacement of its main chain, which in turn propagates to several neighboring residues. This includes a near $10 \AA$ shift in the side chain of $\mathrm{Asn}^{28}$, which makes a hydrogen bond with one of the His ${ }^{137}$ conformers, and large shifts of the $\mathrm{Met}^{130}$ side chain, His ${ }^{136}$, and $\mathrm{Arg}^{135}$. Overall, the $\mathrm{R} 137 \mathrm{H}$ mutation results in significant changes in the local area around the mutation site. Although this seems at odds with the lack of effect of this mutation on $\mathrm{Na}_{\mathrm{V}} 1.5$ function (Fig. 2), it suggests that the structural changes do not disrupt the interface 
$\mathrm{Na} 1.5$

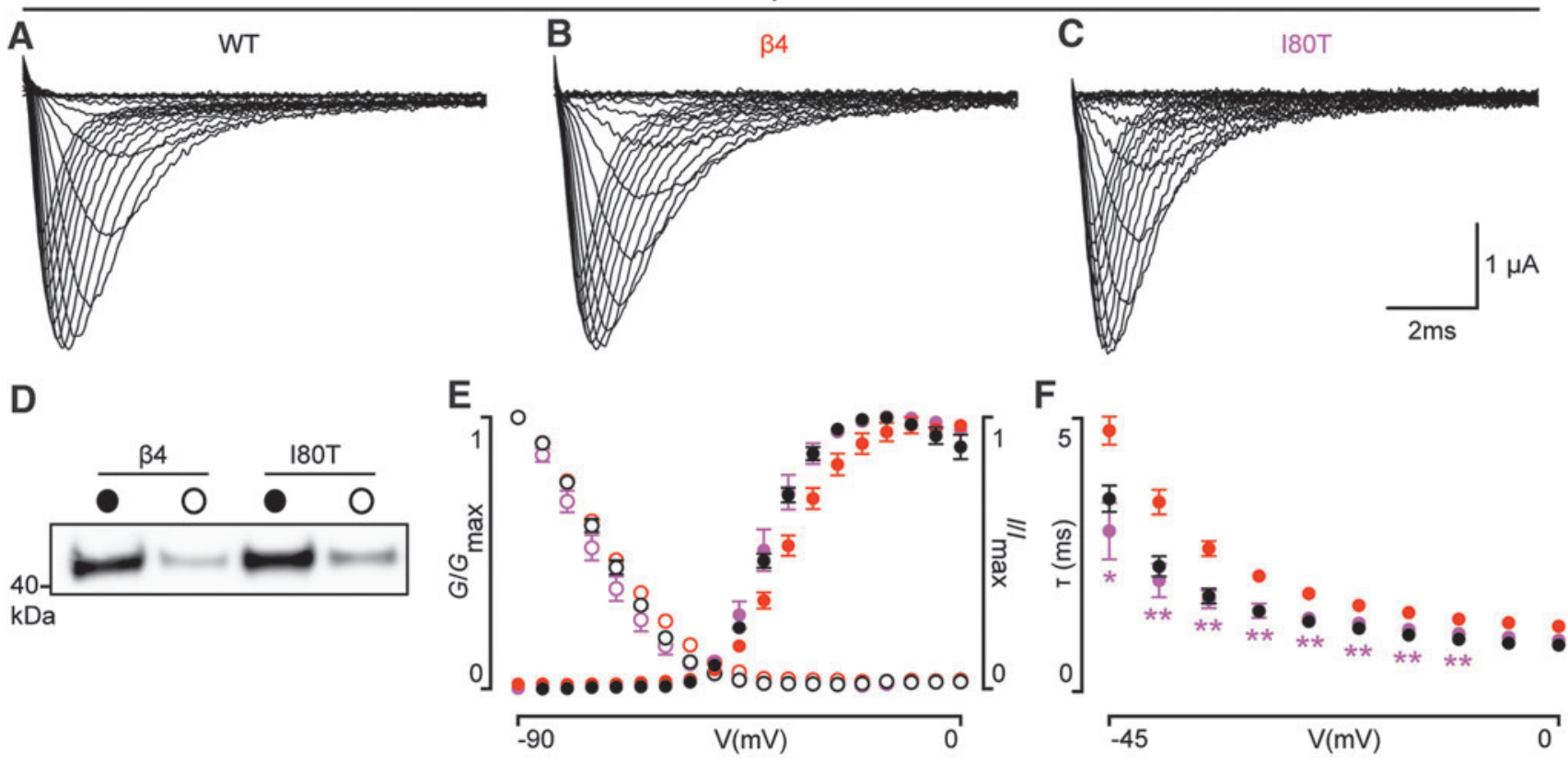

FIG. 1. (A-C) Representative traces of $\mathrm{hNa}{ }_{\mathrm{V}} 1.5$ alone or coexpressed with $\mathrm{h} \beta 4$ (red) or $\mathrm{h} \beta 4^{\mathrm{I}}{ }^{8 \mathrm{~T}}$ (magenta). Oocytes were held at $-120 \mathrm{mV}$ and pulsed from -90 to $15 \mathrm{mV}$ for $50 \mathrm{~ms}$. (D) Western blot probing for the C-terminal myc-tag of h $\beta 4$. Signal is seen for wild-type $\mathrm{h} \beta 4$ as well as $\mathrm{h} \beta 4^{\mathrm{I}}{ }^{80 \mathrm{~T}}$, in both whole cell (closed circles) and surface (open circle) fractions. (E) Normalized conductance voltage $(\mathrm{G}-\mathrm{V}$, filled circles) and channel availability (I-V, open circles) relationships for $\mathrm{hNa}_{\mathrm{V}} 1.5$ either without $\mathrm{h} \beta 4$ (black), with $\mathrm{h} \beta 4$ (red), or with $\mathrm{h} \beta 4$ I80T (magenta). Summary data of G-V and I-V $V_{1 / 2}$ values, slope values, and $p$-values determined by unpaired $t$-test are reported in Table 1 . (F) Rate $(\tau)$ of channel fast inactivation using the same color scheme described above. Time constant was obtained using a single-exponential fit of the current decay phase over a $45 \mathrm{mV}$ range. Error bars in all cases reflect SEM with $n=5-7$; * $p<0.05$ or $* * 0.01$ using one-way ANOVA. ANOVA, analysis of variance; $\mathrm{hNa}_{\mathrm{V}}$, human voltage-gated sodium; SEM, standard error of the mean.

Nav1.5
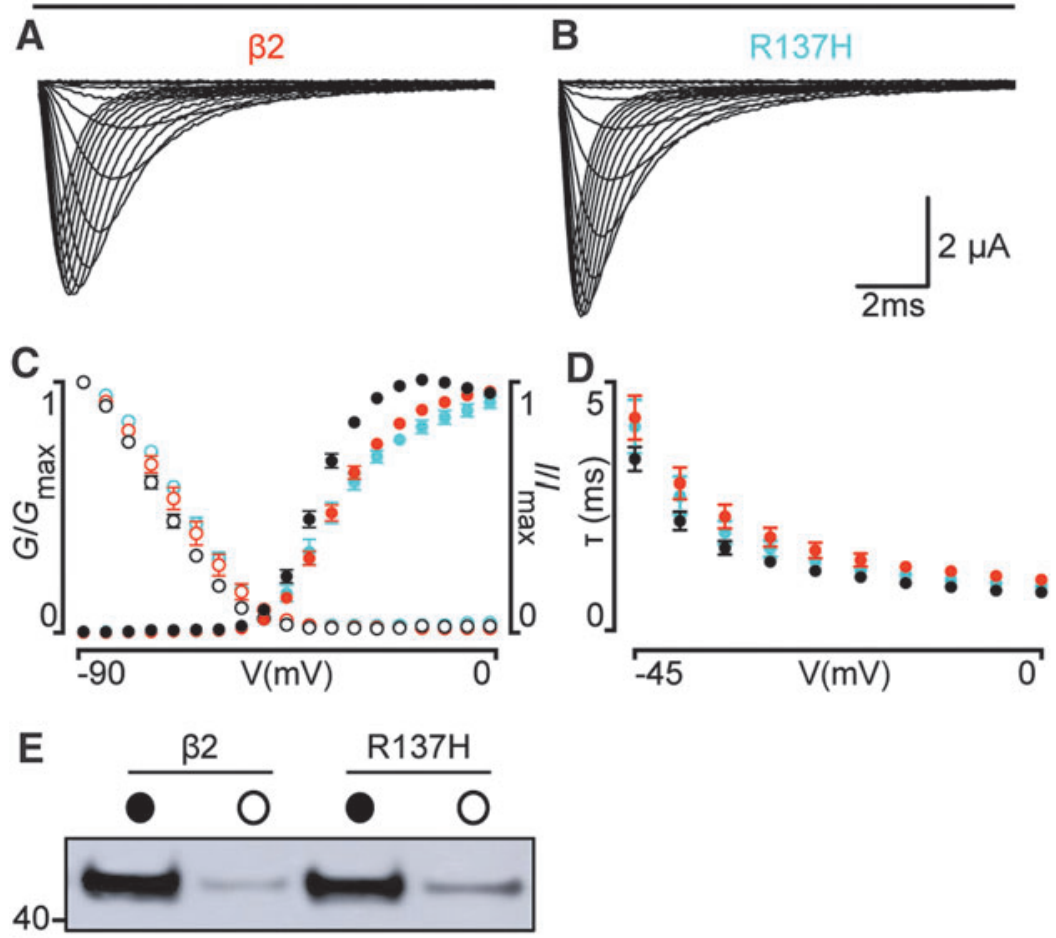

$\mathrm{kDa}$
FIG. 2. (A, B) Representative traces of hNay 1.5 coexpressed with $\mathrm{h} \beta 2$ (red) or $\mathrm{h} \beta 2^{\mathrm{R} 137 \mathrm{H}}$ (cyan). Oocytes were held at $-120 \mathrm{mV}$ and pulsed from -90 to $15 \mathrm{mV}$ for $50 \mathrm{~ms}$. (C) Normalized conductance voltage (G-V, filled circles) and channel availability (I-V, open circles) relationships for $\mathrm{hNa}_{\mathrm{V}} 1.5$ without a $\beta$-subunit (black) or with either $\mathrm{h} \beta 2$ (red) or with $\mathrm{h} \beta 2 \mathrm{R} 137 \mathrm{H}$ (cyan). Summary data of G-V and I-V $V_{1 / 2}$ values, slope values, and $p$-values determined by unpaired $t$-test are reported in Table 1. (D) Rate $(\tau)$ of channel fast inactivation using the same color scheme described above. Time constant was obtained using a single-exponential fit of the current decay phase over a $45 \mathrm{mV}$ range. (E) Western blot probing for the C-terminal myc-tag of $h \beta 2$. Signal is seen for wild-type $\mathrm{h} \beta 2$ as well as $\mathrm{h} \beta 2^{\mathrm{R} 137 \mathrm{H}}$, in both whole cell (closed circles) and surface (open circle) fractions. Error bars in all cases reflect SEM. with $n=5-7 ; * p<0.05$ or $* * 0.01$ using oneway ANOVA. 
A

FIG. 3. (A) Normalized persistent current of $\mathrm{hNa} 1.5$ (black), $\mathrm{hNa}_{\mathrm{V}} 1.5$ $+\mathrm{h} \beta 4$ (red), or $\mathrm{hNa}_{\mathrm{V}} 1.5+\mathrm{h} \beta 4^{\mathrm{I} 80 \mathrm{~T}}$ (magenta) measured $20 \mathrm{~ms}$ after depolarization over a $30 \mathrm{mV}$ range. (B) Normalized recovery from fast inactivation measured over a $50 \mathrm{~ms}$ timeframe using a double-pulse protocol to the maximum current of the $\mathrm{I}-\mathrm{V}$ in Figure 1. Recovery voltage used for this protocol was $-10 \mathrm{mV}$. (C, D) Normalized conductance voltage (G-V, filled circles) and channel availability (I-V, open circles) relationships of $\mathrm{h} \beta 4$ (red) or $\mathrm{h} \beta 4^{180 \mathrm{~T}}$ (magenta) coexpressed with either $\mathrm{hNa}_{\mathrm{V}} 1.1$ (C) or $\mathrm{hNa}_{\mathrm{V}} 1.2$ (D). Both wild-type channels without $\beta$-subunit coexpression are shown in black. Summary data of G-V and I-V $V_{1 / 2}$ values, slope values, and $p$-values determined by unpaired $t$-test are reported in Table 1.

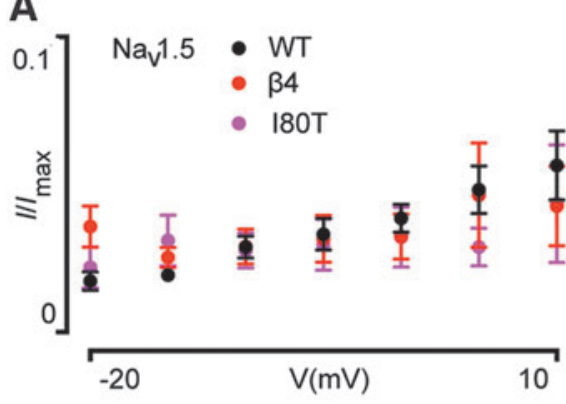

B

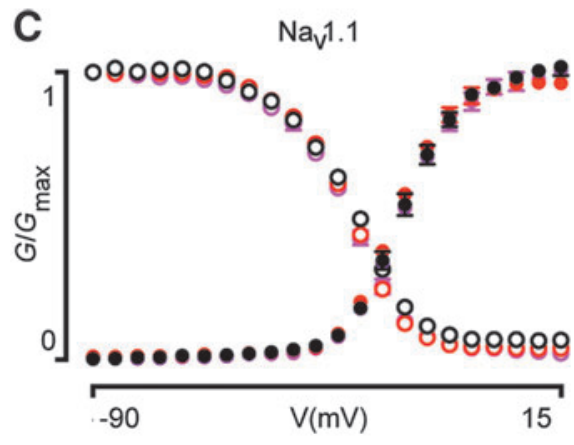

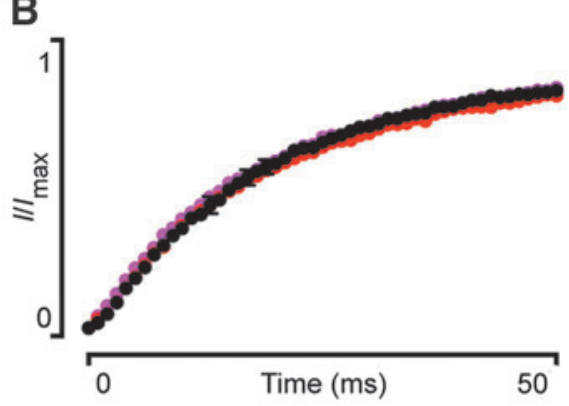

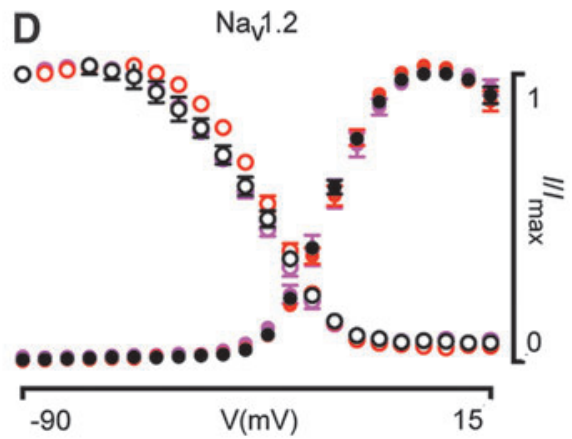

between $\mathrm{h} \beta 2$ and $\mathrm{Na}_{\mathrm{V}} 1.5$. However, this mutation may lead to altered interactions with other $\mathrm{Na}_{\mathrm{V}}$ channel subtypes.

The situation is very different for the $\mathrm{h} \beta 4^{\mathrm{I} 80 \mathrm{~T}}$ mutation. Wild-type and mutant subunit superpose with an RMSD of $0.48 \AA$ for $105 \mathrm{C} \alpha$ atoms (Fig. 5). In wild-type $\mathrm{h} \beta 4$, Ile ${ }^{80}$ is buried within the hydrophobic core of the Ig-like domain, which consists of $\mathrm{Trp}^{68}$, $\mathrm{Leu}^{79}, \mathrm{Val}^{93}$, Leu ${ }^{103}$, and Ile ${ }^{101}$. Substitution by a hydrophilic residue would thus be predicted to be destabilizing. In addition, as Thr is smaller than Ile, the packing is less optimal; resulting in a change in the side chain of Leu ${ }^{103}$, which now adopts a dual side chain conformation. Importantly however, no structural changes are visible on the surface. As the surface of $\mathrm{h} \beta 4$ would be interacting with $\mathrm{Na}_{\mathrm{V}} 1.5$, there is an apparent contradiction with the functional data, which clearly show an effect of the I80T mutation on the $\mathrm{G}-\mathrm{V}$ relationship and steady-state inactivation (Fig. 1). However, as this protein crystallized at low temperature $\left(4^{\circ} \mathrm{C}\right)$, and crystals were flash cooled with liquid $\mathrm{N}_{2}$, a possible temperature-dependent effect on the structure may not be observed. We thus postulate that the suboptimal packing in the $\mathrm{h} \beta 4$ core can result in changes on the surface at elevated temperature, such as used in electrophysiological experiments or present in vivo.

\section{Protein stability}

Amino acid substitutions may perturb protein folding. Although both $\beta$-subunit mutants still express to levels similar to wild type in Xenopus oocytes (Figs. 1 and 2), it is possible that these substitutions cause a thermal destabilization at higher temperatures. Such effect could explain how a mutant, which shows minimal structural changes in a crystallized form at low temperature, can still have a functional effect at physiologically relevant temperatures. We, therefore, prepared purified, recombinantly expressed extracellular subunits of $\mathrm{h} \beta 4, \mathrm{~h} \beta 2$, and the two sequence variants, and utilized Circular Dichroism (CD) to measure thermal melting curves (Fig. 6). Mon- itoring the $\mathrm{CD}$ signal at $213 \mathrm{~nm}$, we increased the temperature from $25^{\circ} \mathrm{C}$ to $95^{\circ} \mathrm{C}$ in increments of $0.5^{\circ} \mathrm{C}$. Wild-type $\mathrm{h} \beta 4$ displays a melting temperature $\left(T_{\mathrm{M}}\right)$ of $61.1^{\circ} \mathrm{C} \pm 0.3^{\circ} \mathrm{C}$, whereas the I80T mutation results in a significant destabilization with a $T_{\mathrm{M}}$ of $51.4^{\circ} \mathrm{C} \pm 0.1^{\circ} \mathrm{C}$ (Fig. 6).

Although the actual $T_{\mathrm{M}}$ in the context of a native cell, under oxidizing conditions and in the presence of a $\mathrm{Na}_{\mathrm{V}}$ channel is unknown, our observation that the mutation has an effect on stability in our assay hints at possible structural changes at elevated temperatures. Although the $T_{\mathrm{M}}$ is well above $37^{\circ} \mathrm{C}$, a subtle degree of unfolding is already present at this temperature. Of note, the CD signal measures secondary structure, and it is thus conceivable that significant local structural perturbations, which do not affect secondary structure content, already occur at physiologically relevant temperatures, which would affect the interface between $\mathrm{h} \beta 4$ and $\mathrm{Na}_{\mathrm{V}} 1.5$. Wild-type $\mathrm{h} \beta 2$ is significantly less stable than $\mathrm{h} \beta 4$, with a $T_{\mathrm{M}}$ of $47.4^{\circ} \mathrm{C} \pm 0.1^{\circ} \mathrm{C}$. However, in this case, no significant impact on protein stability was observed for the $\mathrm{R} 137 \mathrm{H}$ mutation $\left(T_{\mathrm{M}}=45.8^{\circ} \mathrm{C} \pm 0.1^{\circ} \mathrm{C}\right)$.

\section{Mapping $\beta$-subunit variants on cryoelectron microscopy structures}

Next, we wondered whether the $\beta$-subunit mutations studied here are part of an interface with $\mathrm{Na}_{\mathrm{V}} 1.5$. A cryoelectron microscopy (EM) structure is available for $\mathrm{Na}_{\mathrm{V}} 1.5$ as well as crystal structures of cytosolic portions in complex with auxiliary proteins $9,10,12-15,31$ and also cryo-EM structures of the related $\mathrm{Na}_{\mathrm{V}} 1.2, \mathrm{Na}_{\mathrm{V}} 1.4$, and $\mathrm{Na}_{\mathrm{v}} 1.7$ channels, in complex with one or more auxiliary $\beta$-subunits. ${ }^{7,8,32}$ This includes structures of $\mathrm{hNa}_{\mathrm{V}} 1.2$ in complex with $\beta 2$ (PDB $6 \mathrm{~J} 8 \mathrm{E}$ ), $\mathrm{hNa}_{\mathrm{V}} 1.4$ in complex with $\beta 1$ (PDB 6AGF), and $\mathrm{hNa}_{\mathrm{V}} 1.7$ in complex with $\beta 1$ and $\beta 2$ (PDB 6J8G). In each of the $\beta 2$ complexes, a disulfide bond was observed with the pore-forming subunit. This corresponds to $\mathrm{Cys}^{910}$ in $\mathrm{Na}_{\mathrm{V}} 1.2$, a residue we predicted to form a disulfide bond with $\mathrm{Cys}^{55}$ in $\mathrm{h} \beta 2 .{ }^{17}$ Although no cryo- 
Table 2. Data Collection AND ReFinement Statistics

\begin{tabular}{|c|c|c|}
\hline Data collection & $\beta 4-C 58 A / I 80 T$ & $\beta 2-C 55 A / R 137 H$ \\
\hline \multicolumn{3}{|l|}{ PDB code } \\
\hline Space group & $P 3_{2} 21$ & $P 2_{1} 2_{1} 2_{1}$ \\
\hline \multicolumn{3}{|l|}{ Cell dimensions } \\
\hline$a, b, c(\AA)$ & $43.1,43.1,107.5$ & $40.3,53.6,59.3$ \\
\hline$\alpha, \beta, \gamma\left({ }^{\circ}\right)$ & $90,90,120$ & $90,90,90$ \\
\hline \multirow[t]{2}{*}{ Resolution (A) } & $50-1.62$ & $40.3-1.45$ \\
\hline & $(1.68-1.65)^{\mathrm{a}, \mathrm{b}}$ & $(1.53-1.45)^{\mathrm{a}, \mathrm{b}}$ \\
\hline$R_{\text {meas }}$ & $7.9(65.4)$ & $4.3(62.5)$ \\
\hline$I / \sigma I$ & $33.5(1.9)$ & $24.4(2.75)$ \\
\hline Completeness (\%) & $99.8(99.4)$ & $99.9(99.6)$ \\
\hline Redundancy & $5.1(4.7)$ & $6.9(6.54)$ \\
\hline $\mathrm{CC}(1 / 2)^{\mathrm{c}}$ & 76.0 & 92.9 \\
\hline \multicolumn{3}{|l|}{ Refinement } \\
\hline Resolution ( $\mathrm{A})$ & $37.3-1.62$ & $40.3-1.45$ \\
\hline No. of reflections & 15397 & 43929 \\
\hline Molecules & 1 & 1 \\
\hline$R_{\text {work }} / R_{\text {free }}$ & $18.47 / 20.81$ & $14.8 / 18.35$ \\
\hline \multicolumn{3}{|l|}{ No. of atoms } \\
\hline Protein & 990 & 2436 \\
\hline Ligand & - & 28 \\
\hline Water & 147 & 163 \\
\hline \multicolumn{3}{|l|}{$B$-factors } \\
\hline Protein & 33.2 & 23.9 \\
\hline Ligand & - & 44.2 \\
\hline Water & 48.2 & 34.6 \\
\hline \multicolumn{3}{|l|}{ R.m.s. deviations } \\
\hline Bond lengths $(\AA)$ & 0.012 & 0.013 \\
\hline Bond angles $\left(^{\circ}\right)$ & 1.229 & 1.623 \\
\hline \multicolumn{3}{|l|}{ Ramachandran plot ${ }^{\mathrm{d}}$} \\
\hline Favored $(\%)$ & 96.3 & 97.6 \\
\hline Allowed (\%) & 3.7 & 2.4 \\
\hline Disallowed (\%) & - & - \\
\hline
\end{tabular}

${ }^{\mathrm{a}}$ One crystal for each structure was used for data collection and structure determination.

${ }^{\mathrm{b}}$ Values in parentheses are for highest-resolution shell.

${ }^{\mathrm{c}}$ Value is for highest-resolution shell.

${ }^{\mathrm{d}}$ Using Procheck of CCP4 package.
EM structures have captured $\beta 4$ in complex with a $\mathrm{Na}_{V}$ channel, this subunit is also predicted to make a similar disulfide bond. ${ }^{17,18}$ However, as $\mathrm{Na}_{\mathrm{v}} 1.5$ does not have a Cys residue at the corresponding position, the interaction between $\beta 2 / \beta 4$ with $\mathrm{Na}_{\mathrm{V}} 1.5$ cannot rely on this disulfide bridge. ${ }^{17,18,31}$

Figure 7 shows the structure of the $\mathrm{Na}_{\mathrm{V}} 1.2-\beta 2$ complex (PDB 6J8E), illustrating that the interaction also involves several other residues that make extensive interactions with the Domain II pore-forming region of the channel. From these data, it is clear that the $\mathrm{R} 137 \mathrm{H}$ variant is in a position to perturb this interaction. Although R137 is not directly located at the interface, the structural changes we observed for this mutation affect residues located at the $\beta 2-\mathrm{Na}_{\mathrm{V}} 1.2$ interface, including $\mathrm{Arg}^{28}{ }^{28} \mathrm{Arg}^{135}$, and $\mathrm{His}^{136}$. Thus, the $\mathrm{h} \beta 2 \mathrm{R} 137 \mathrm{H}$ variant could perturb the interface with $\mathrm{Na}_{\mathrm{V}} 1.2$, and likely also closely related $\mathrm{Na}_{\mathrm{V}}$ channel subtypes expressed in the heart (i.e., $\left.\mathrm{Na}_{\mathrm{V}} 1.1-1.3\right){ }^{33}$ Since $\mathrm{h} \beta 2^{\mathrm{R} 137 \mathrm{H}}$ has no functional effect on $\mathrm{Na}_{\mathrm{V}} 1.5$ compared with $\mathrm{h} \beta 2$, whereas $\mathrm{h} \beta 4^{\mathrm{I} 00 \mathrm{~T}}$ does, it seems unlikely that $\beta 2$ and $\beta 4$ interact with $\mathrm{Na}_{\mathrm{V}} 1.5$ similar to the $\mathrm{Na}_{\mathrm{V}} 1.2-\beta 2$ complex. Indeed, $\mathrm{Na}_{\mathrm{V}} 1.5$ lacks the Cys equivalent to position 910 in $\mathrm{Na}_{\mathrm{V}} 1.2$, suggesting that the manner in which these two $\beta$-subunits interact with $\mathrm{Na}_{\mathrm{V}} 1.5$ is fundamentally different. ${ }^{17,31,34}$

\section{$N a_{V} 1.2$ gating and $\beta 2^{R 137 H}$}

Since neuronal $\mathrm{Na}_{\mathrm{V}}$ channel subtypes expressed in the heart ${ }^{2}$ contain the Cys equivalent to position 910 in $\mathrm{Na}_{\mathrm{V}} 1.2,{ }^{7,17}$ the structural changes induced by the $\beta 2 \mathrm{R} 137 \mathrm{H}$ mutation may disrupt channel function. To test this hypothesis with links to available structural data, we used $\mathrm{hNa}_{\mathrm{V}} 1.2$ as our model channel, coexpressed with wild-type $\beta 2$ or $\beta 2^{\mathrm{R} 137 \mathrm{H}}$. While we observe no changes in channel availability of $\mathrm{hNa}_{\mathrm{V}} 1.2$, the $\mathrm{G}-\mathrm{V}$ relationship and fast inactivation in the presence of $\beta 2^{\mathrm{R} 137 \mathrm{H}}$ differs substantially from that observed with wild-type $\beta 2(p<0.001)$ and is virtually identical to the condition when no subunit is present (Fig. 8).
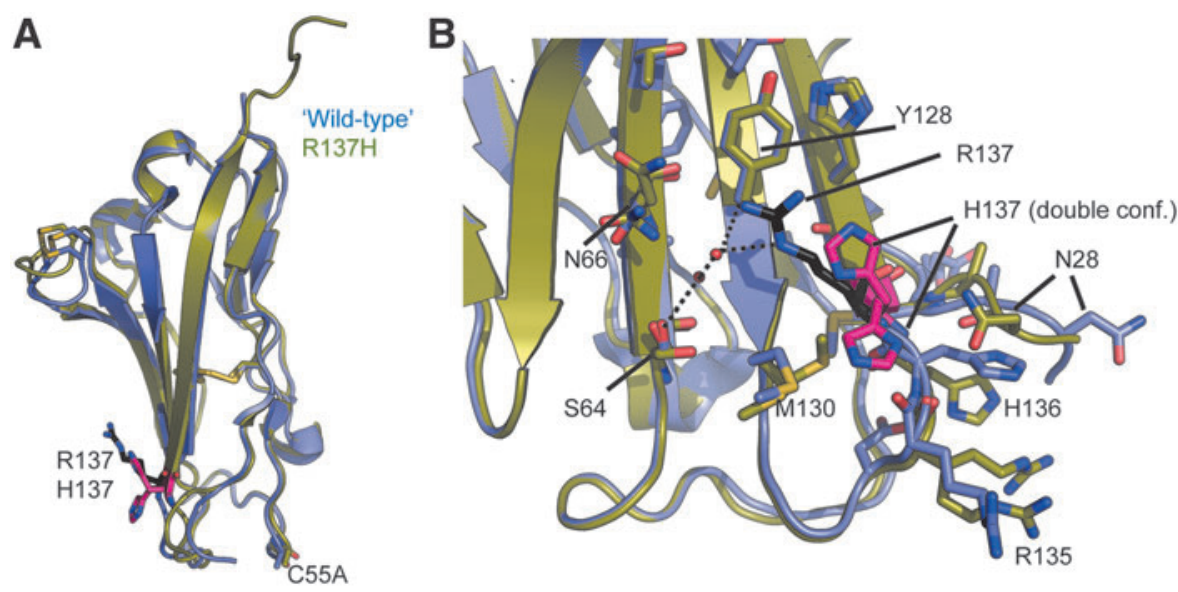

FIG. 4. Crystallographic analysis of $\mathrm{h} \beta 2^{\mathrm{R} 137 \mathrm{H}}$. Wild-type $\mathrm{h} \beta 2$ (containing the C55A mutation to facilitate crystallization ${ }^{17}$ ) is shown in blue, and the R137H mutant in green. R137 is shown in black sticks and H137 in pink. (A) Overall superposition of both structures. (B) Details around the site of the mutation. Selected residues are shown in sticks and labeled. Hydrogen bonds are shown with dotted lines. In wild-type $\mathrm{h} \beta 2$, the $\operatorname{Arg} 137$ side chain is involved in a hydrogen bond network as well as a cation $-\pi$ interaction with Y128. Substitution by H137 results in multiple changes in side chain orientations, as well as the main chain conformation of the $\mathrm{N}$-terminal region around $\mathrm{N} 28$. 
FIG. 5. Crystallographic analysis of $\mathrm{h} \beta 4^{\mathrm{I}}{ }^{\mathrm{I} 0 \mathrm{~T}}$. Wild-type $\mathrm{h} \beta 4$ (containing the C58A mutation to facilitate crystallization) is shown in blue, and the I80T mutant in orange. I80 is shown in black sticks, and T80 in pink. (A) Overall superposition of both structures. (B) Details around the site of the mutation. Select residues are shown in sticks and labeled. I80 is involved in packing of the hydrophobic core, making interactions with other hydrophobic residues. Substitution by Thr results in minor structural changes, including a rearrangement of the I101 side chain conformation.
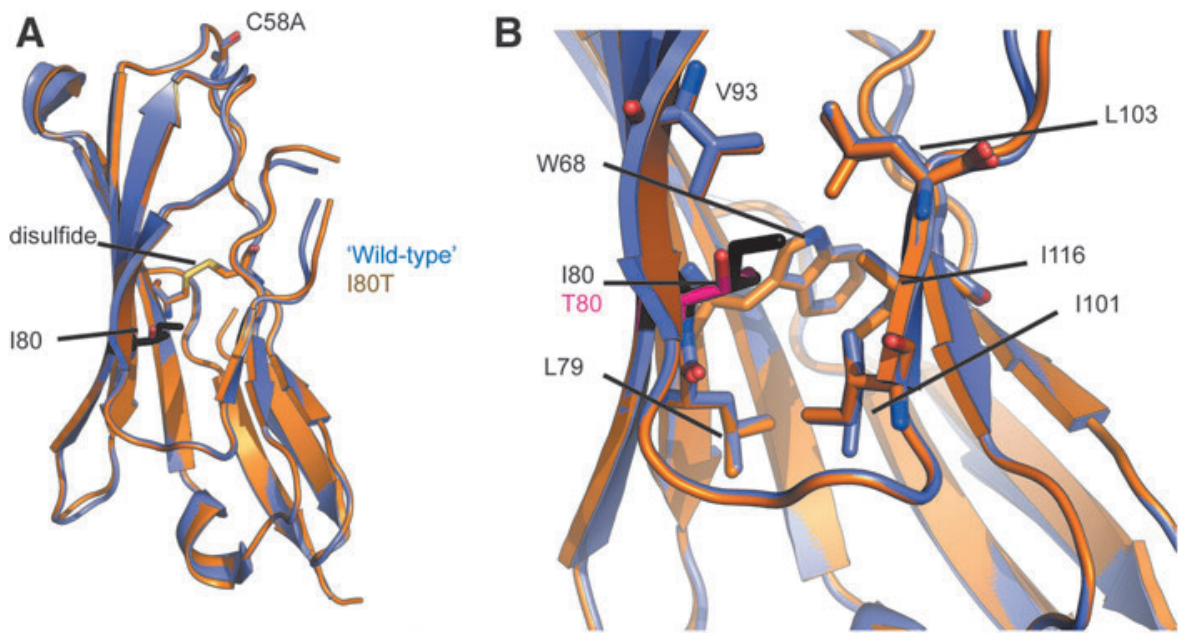

\section{Discussion}

We investigated the functional and structural effects of two $\beta$-subunit variants, $S C N 4 B$ (p.Ile80Thr) and $S C N 2 B$ (p.Arg137His), found in patients with familial atrial fibrillation and LQTS 10. Our functional investigation showed a direct effect of the $\mathrm{h} \beta 4^{\mathrm{I} 80 \mathrm{~T}}$, but not the $\mathrm{h} \beta 2^{\mathrm{R} 137 \mathrm{H}}$ variant, on the function of $\mathrm{hNa}_{\mathrm{V}} 1.5$ (Figs. 1 and 2). However, structural investigation using X-ray crystallography revealed opposite results, with $\mathrm{h} \beta 2^{\mathrm{R} 137 \mathrm{H}}$ causing significant structural changes and $\mathrm{h} \beta 4^{\mathrm{I}}{ }^{\mathrm{I} 0 \mathrm{~T}}$ resembling the wild-type protein under the crystallization conditions used (Figs. 4 and 5). A structural change does not necessarily have to cause a functional impact, especially if the perturbation is local and does not affect a protein-protein interface. The results presented here suggest that the region around $\mathrm{Arg}^{137}$ in $\mathrm{h} \beta 2$ may not be involved in the interface with $\mathrm{Na}_{\mathrm{V}} 1.5$. However, the $\mathrm{h} \beta 4^{\mathrm{I}}{ }^{\mathrm{I}} \mathrm{T}$ results seem contradictory given that the absence of significant structural changes suggests that the interface with $\mathrm{Na}_{\mathrm{V}} 1.5$ should be unaffected.

To better understand this conundrum, it is important to consider a possible effect of temperature. Proteins will unfold, both locally and globally, with rising temperatures, and a mutation could affect this thermal stability. ${ }^{35,36}$ If any unfolding of the mutant occurs at physiological temperatures, and this affects a relevant interface, then the mutant is likely to have a functional effect. In this regard, the $\mathrm{h} \beta 4^{\mathrm{I}}{ }^{\mathrm{IOT}}$ caused a significant reduction in thermal stability (Fig. 6). This is not surprising, as our structural analysis showed that $\mathrm{Ile}^{80}$ is buried in a hydrophobic core, and substitution by a hydrophilic residue should be destabilizing. One could thus postulate that the mutation causes local changes in structure at or near the interface between $\mathrm{h} \beta 4$ and $\mathrm{Na}_{\mathrm{V}} 1.5$ at physiologically relevant temperatures, leading to alterations in channel gating. Importantly, thermal melting curves obtained via $C D$ only represent changes in secondary structure, so small structural perturbations may not be measured. Thus, although the melting temperature is above a physiologically relevant temperature, small local changes that do not affect secondary structure are still possible at physiological temperatures. In addition, the altered stability can affect the dynamics of $\mathrm{h} \beta 4$, thus affecting its interactions with $\mathrm{Na}_{\mathrm{V}} 1.5$ indirectly.

Temperature-dependent effects have previously been reported as a result of mutations in $\mathrm{Na}_{\mathrm{V}} 1.5$. This includes amino acid substitutions in the EF-hand domain leading to thermal destabilization of this locus. ${ }^{37,38}$ Thermal destabilization induced by disease-causing mutations has also been described in other ion channel families. ${ }^{39,40}$ Since the $\mathrm{h} \beta 4^{\mathrm{I}{ }^{\mathrm{I} 0 \mathrm{~T}}}$ mutation was found in a LQTS patient, an increase in body temperature (e.g., fever or exercise) could elicit structural and functional changes in the cardiac $\mathrm{Na}_{\mathrm{V}}$ channel complex, thereby causing an increase in QT interval time and subsequently an increased risk to develop torsade de pointes and polymorphic ventricular tachycardia. Indeed, fever-related ventricular arrhythmia and sudden death have been associated extensively with $\mathrm{BrS}^{41}$; however, few reports also describe fever-induced QT
FIG. 6. Thermal melting curves monitored through $\mathrm{CD}$ recorded at $213 \mathrm{~nm}$.(A) Wild-type $\mathrm{h} \beta 4$ (containing the $\mathrm{C} 58$ mutation-black) and the I80T mutant (red). (B) Wild-type $\mathrm{h} \beta 2$ (containing the C58A mutationblack) and the R137H mutant (green). The $T_{\mathrm{M}}$ values were obtained from the midpoints of the transitions. $\mathrm{CD}$, circular dichroism.
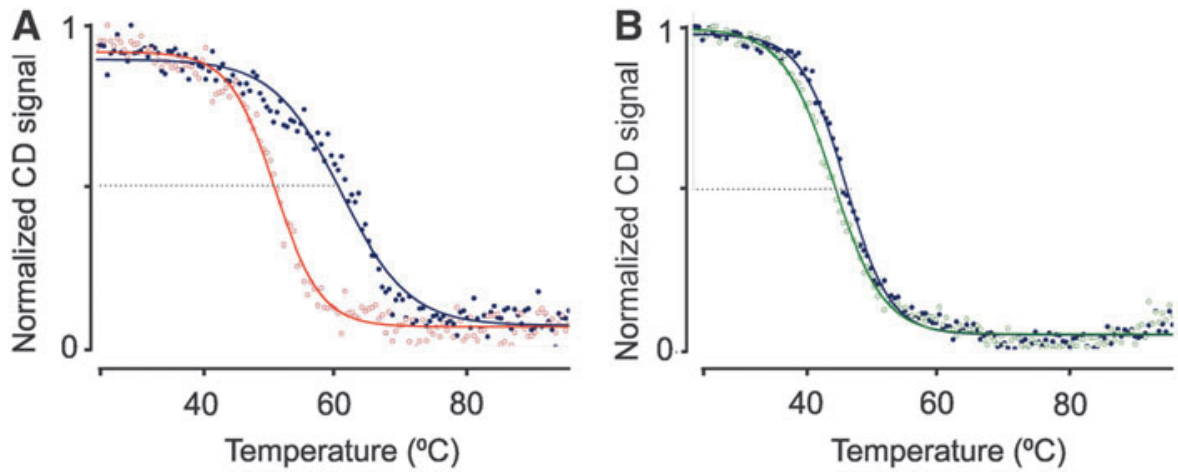
A

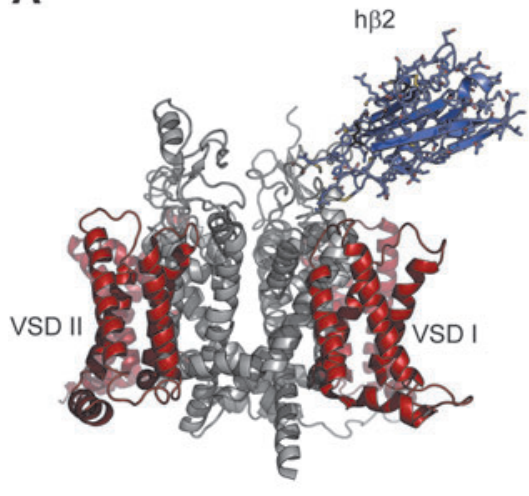

B

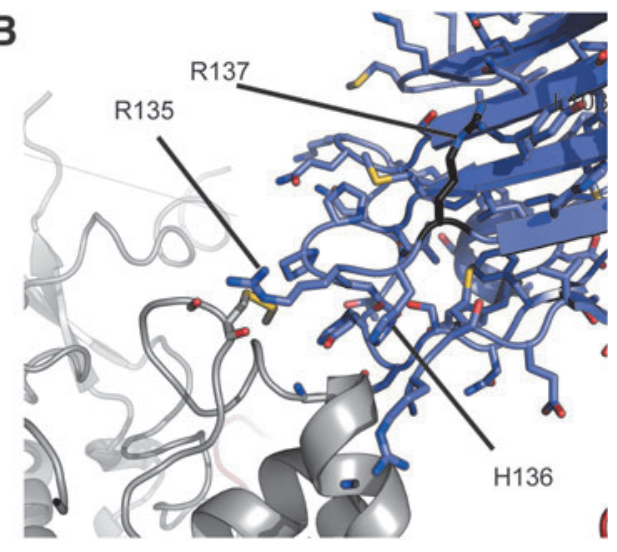

FIG. 7. Mapping the mutation sites on the Nav1.2- $\beta 2$ cryo-EM structure. (A) Overall cryo-EM structure of $\mathrm{Na}_{\mathrm{V}} 1.2$ bound to $\mathrm{h} \beta 2$ (PDB 6J8E). The pore-forming domain and VSDs are shown in gray and red, respectively, and $\mathrm{h} \beta 2$ in blue. (B). Details of the interaction. Selected residues in $\mathrm{h} \beta 2$ are labeled. Notice that several of the $\mathrm{h} \beta 2$ residues, shown to be affected by the $\mathrm{R} 137 \mathrm{H}$ mutation, are directly at the interface with $\mathrm{Na}_{\mathrm{V}} 1.2$. EM, electron microscopy; VSDs, voltage-sensing domains. prolongation and ventricular arrhythmias in individuals with type 2 congenital LQTS. ${ }^{42}$ As such, it is possible that the $S C N 4 B$ p.Ile80Thr mutation could favor the appearance of an arrhythmic phenotype in concomitance with fever. We note that this remains a hypothesis, and it needs to be shown whether the mutation elicits small structural or dynamic changes at physiological temperatures.

Although the $\mathrm{h} \beta 2^{\mathrm{R} 137 \mathrm{H}}$ variant did not appear to affect any of the electrophysiological properties of $\mathrm{Na}_{\mathrm{V}} 1.5$, mapping of the mutation on the $\mathrm{Na}_{\mathrm{V}} 1.2-\mathrm{h} \beta 2$ cryo-EM structure showed that this residue can affect channel-subunit interactions. Although not directly involved in the interface, we found that the structural changes we observed affect residues directly participating in their interaction, including R135 and H136 (Fig. 7). Subsequently, $\mathrm{h} \beta 2^{\mathrm{R} 137 \mathrm{H}}$ indeed restored $\mathrm{hNa} \mathrm{V}_{\mathrm{V}} 1.2$ function as if no $\mathrm{h} \beta 2$-subunit was present when considering channel closure (i.e., the fast inactivation process) (Fig. 8). Since several neuronal $\mathrm{Na}_{\mathrm{V}}$ channel isoforms are expressed in the heart at functionally important locations, ${ }^{2,33}$ our result hints at a contribution of this $\mathrm{h} \beta 2$ variant to arrhythmia, ${ }^{43,44}$ despite the absence of functional effects on the main cardiac isoform, $\mathrm{Na}_{\mathrm{V}} 1.5$. From a clinical perspective, $\mathrm{h} \beta 2^{\mathrm{R} 137 \mathrm{H}}$ was found in a patient with familial atrial fibrillation and since intrinsic and extrinsic cardiac innervations are pivotal in determining physiological modulations in cardiomyocytes, ${ }^{45}$ it may be feasible that this mutation can modify neural activity in the heart.

Finally, it is worth noting that the extracellular Ig domain of $\beta$-subunits can participate in homo- and heterophilic cell adhesion processes, which may have implications for cardiomyocyte function. ${ }^{34}$ Combined with previous work, ${ }^{17,18,30,31,34,46,47}$ it is unlikely that the Ig domains of $\mathrm{h} \beta 2$ and $\mathrm{h} \beta 4$ interact with $\mathrm{Na}_{\mathrm{V}} 1.5$ in the same way that they do with other $\mathrm{Na}_{\mathrm{V}}$ channel subtypes, since $\mathrm{Na}_{\mathrm{V}} 1.5$ does not have a free Cys residue on the domain II extracellular loop. ${ }^{17,31}$ As such, the exact interface of $\mathrm{h} \beta 2$ or $\mathrm{h} \beta 4$ with $\mathrm{Na}_{\mathrm{V}} 1.5$ remains to be described, but likely does not involve $\mathrm{h} \beta 2$ residue $\mathrm{R} 137$ or the neighboring residues whose positions are affected by the $\mathrm{R} 137 \mathrm{H}$ mutation. Ig domains of $\mathrm{h} \beta 4$ (and presumably $\mathrm{h} \beta 2$ ) can form both cis and trans cell adhesion contacts and some of the same amino acids involved in binding to the $\mathrm{Na}_{\mathrm{V}}$ channel also contribute to these cis interactions. ${ }^{34}$ Therefore, $\mathrm{h} \beta 2$ and $\mathrm{h} \beta 4 \mathrm{Ig}$ domains that associate with $\mathrm{Na}_{\mathrm{V}} 1.5$ may be involved in crosslinking of associated channels suggesting the involvement of higher-order assemblies in potentially causing cardiac defects and illustrating the complexities in linking genetic data to patient phenotype.

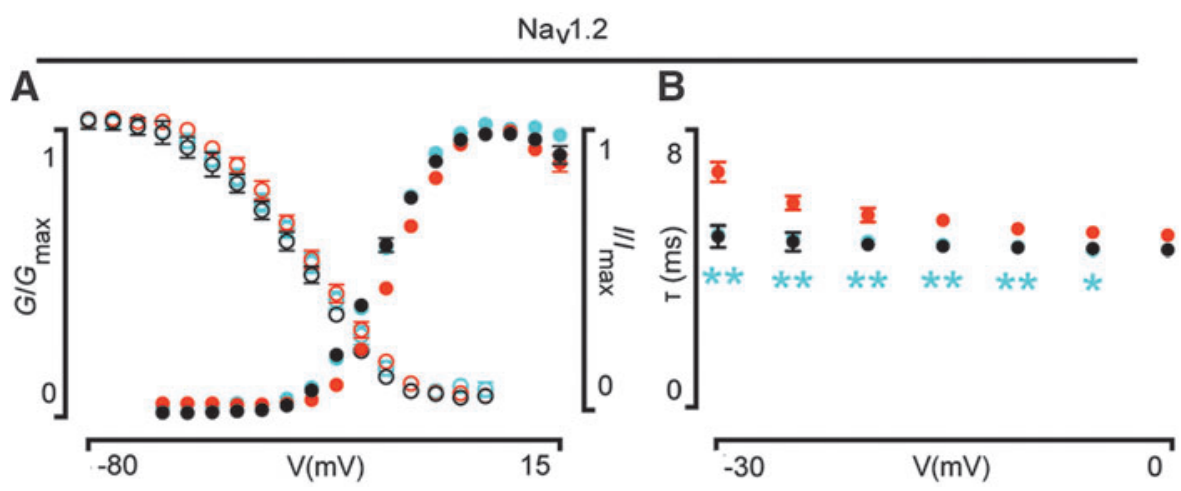

FIG. 8. (A) Normalized conductance voltage (G-V, filled circles) and channel availability (I-V, open circles) relationships for hNav 1.2 without a $\beta$-subunit (black) or with either $\mathrm{h} \beta 2$ (red) or with $\mathrm{h} \beta 2 \mathrm{R} 137 \mathrm{H}$ (cyan). Summary data of G-V and I-V $V_{1 / 2}$ values, slope values, and $p$-values determined by unpaired $t$-test are reported in Table 1 . (B) Rate $(\tau)$ of channel fast inactivation using the same color scheme described above. Time constant was obtained using a single-exponential fit of the current decay phase over a $45 \mathrm{mV}$ range. Error bars in all cases reflect SEM. with $n=5 ; * p<0.05$ or $* * 0.01$ using one-way ANOVA. 


\section{Author Contributions}

F.B and F.V.P. conceived the experiments, analyzed data, and wrote the article. J.D.W., L.C., and A.S. helped write the article and interpret (clinical) data. S.D. performed all crystallographic and thermal melt experiments. J.P.L. performed all electrophysiology and biochemical experiments. All coauthors have reviewed and approved of the article before submission.

\section{Acknowledgments}

We acknowledge the staff at the Stanford Synchrotron Radiation Lightsource beamline BL9-2, and the Advanced Photon Source beamline 23-ID-D.

\section{Disclaimer}

The article has been submitted solely to this journal and is not published, in press, or submitted elsewhere.

\section{Author Disclosure Statement}

No competing financial interests exist.

\section{Funding Information}

J.P.L. was supported by the James H. Gilliam Fellowships for Advanced Study through the Howard Hughes Medical Institute. F.B. received support from the National Institutes of Health (1R01NS091352). F.V.P. received support for this study by a grant from the Canadian Institute for Health Research (CIHR, PJT-148632). The funders had no role in study design, data collection and analysis, decision to publish, or preparation of the article.

\section{References}

1. Ahern CA, Payandeh J, Bosmans F, et al. The hitchhiker's guide to the voltage-gated sodium channel galaxy. J Gen Physiol 2016;147:1-24.

2. Kaufmann SG, Westenbroek RE, Maass AH, et al. Distribution and function of sodium channel subtypes in human atrial myocardium. J Mol Cell Cardiol 2013;61: 133-141.

3. Rook MB, Evers MM, Vos MA, et al. Biology of cardiac sodium channel Nav1.5 expression. Cardiovasc Res 2012; 93:12-23.

4. George AL, Jr. Inherited disorders of voltage-gated sodium channels. J Clin Invest 2005;115:1990-1999.

5. Brugada P, Brugada J. Right bundle branch block, persistent ST segment elevation and sudden cardiac death: A distinct clinical and electrocardiographic syndrome. A multicenter report. J Am Coll Cardiol 1992;20:1391-1396.

6. O'Malley HA, Isom LL. Sodium channel beta subunits: Emerging targets in channelopathies. Annu Rev Physiol 2015;77:481-504.

7. Pan X, Li Z, Huang X, et al. Molecular basis for pore blockade of human Na+ channel Nav1.2 by the muconotoxin KIIIA. Science 2019;363:1309-1313.

8. Shen H, Liu D, Wu K, et al. Structures of human Nav1.7 channel in complex with auxiliary subunits and animal toxins. Science 2019;363:1303-1308.

9. Wang C, Chung BC, Yan H, et al. Crystal structure of the ternary complex of a Nav C-terminal domain, a fibroblast growth factor homologous factor, and calmodulin. Structure 2012;20:1167-1176.

10. Wang C, Chung BC, Yan H, et al. Structural analyses of $\mathrm{Ca}(2+) / \mathrm{CaM}$ interaction with Nav channel C-termini reveal mechanisms of calcium-dependent regulation. Nat Commun 2014;5:4896.

11. Yan H, Wang C, Marx SO, et al. Calmodulin limits pathogenic Na+ channel persistent current. J Gen Physiol 2017; 149:277-293.

12. Gabelli SB, Boto A, Kuhns VH, et al. Regulation of the Nav1.5 cytoplasmic domain by calmodulin. Nat Commun 2014;5:5126.

13. Yoder JB, Ben-Johny M, Farinelli F, et al. Ca(2+)dependent regulation of sodium channels Nav1.4 and Nav1.5 is controlled by the post-IQ motif. Nat Commun 2019;10:1514.

14. Sarhan MF, Tung CC, Van Petegem F, et al. Crystallographic basis for calcium regulation of sodium channels. Proc Natl Acad Sci U S A 2012;109:3558-3563.

15. Johnson CN, Potet F, Thompson MK, et al. A mechanism of calmodulin modulation of the human cardiac sodium channel. Structure 2018;26:683-694 e683.

16. Gardill BR, Rivera-Acevedo RE, Tung CC, et al. Crystal structures of $\mathrm{Ca}(2+)$-calmodulin bound to Nav C-terminal regions suggest role for $\mathrm{EF}-$ hand domain in binding and inactivation. Proc Natl Acad Sci U S A 2019;116:1076310772.

17. Das S, Gilchrist J, Bosmans F, et al. Binary architecture of the Nav1.2-beta2 signaling complex. eLife 2016;5:e10960.

18. Gilchrist J, Das S, Van Petegem F, et al. Crystallographic insights into sodium-channel modulation by the beta4 subunit. Proc Natl Acad Sci U S A 2013;110:E5016E5024.

19. Namadurai S, Balasuriya D, Rajappa R, et al. Crystal structure and molecular imaging of the Nav channel beta3 subunit indicates a trimeric assembly. J Biol Chem 2014; 289:10797-10811.

20. Watanabe H, Koopmann TT, Le Scouarnec S, et al. Sodium channel beta1 subunit mutations associated with Brugada syndrome and cardiac conduction disease in humans. J Clin Invest 2008;118:2260-2268.

21. Pancaroglu R, Van Petegem F. Calcium channelopathies: Structural insights into disorders of the muscle excitationcontraction complex. Annu Rev Genet 2018;52:373396.

22. Gilchrist J, Dutton S, Diaz-Bustamante M, et al. Nav1.1 modulation by a novel triazole compound attenuates epileptic seizures in rodents. ACS Chem Biol 2014;9:12041212.

23. Kabsch W. XDS. Acta Crystallogr D Biol Crystallogr 2010; 66:125-132.

24. Minor W, Cymborowski M, Otwinowski Z, et al. HKL3000: The integration of data reduction and structure solution-From diffraction images to an initial model in minutes. Acta Crystallogr D Biol Crystallogr 2006;62:859866.

25. McCoy AJ, Grosse-Kunstleve RW, Adams PD, et al. Phaser crystallographic software. J Appl Crystallogr 2007;40: 658-674.

26. Emsley P, Lohkamp B, Scott WG, et al. Features and development of Coot. Acta Crystallogr D Biol Crystallogr 2010;66:486-501.

27. Adams PD, Afonine PV, Bunkoczi G, et al. PHENIX: A comprehensive Python-based system for macromolecular 
structure solution. Acta Crystallogr D Biol Crystallogr 2010;66:213-221.

28. Brunger AT, Adams PD, Clore GM, et al. Crystallography \& NMR system: A new software suite for macromolecular structure determination. Acta Crystallogr D Biol Crystallogr 1998;54:905-921.

29. Li RG, Wang Q, Xu YJ, et al. Mutations of the SCN4Bencoded sodium channel beta4 subunit in familial atrial fibrillation. Int J Mol Med 2013;32:144-150.

30. Medeiros-Domingo A, Kaku T, Tester DJ, et al. SCN4Bencoded sodium channel beta4 subunit in congenital longQT syndrome. Circulation 2007;116:134-142.

31. Jiang DH, Shi H, Tonggu LG, et al. Structure of the cardiac sodium channel. Cell 2020;180:122-134.e10.

32. Yin G, Hassan F, Haroun AR, et al. Arrhythmogenic calmodulin mutations disrupt intracellular cardiomyocyte $\mathrm{Ca} 2+$ regulation by distinct mechanisms. J Am Heart Assoc 2014;3:e000996.

33. Veeraraghavan R, Gyorke S, Radwanski PB. Neuronal sodium channels: Emerging components of the nanomachinery of cardiac calcium cycling. J Physiol 2017;595: 3823-3834.

34. Salvage SC, Huang CL, Jackson AP. Cell-adhesion properties of beta-subunits in the regulation of cardiomyocyte sodium channels. Biomolecules 2020;10:989.

35. Clapham DE, Miller C. A thermodynamic framework for understanding temperature sensing by transient receptor potential (TRP) channels. Proc Natl Acad Sci U S A 2011; 108:19492-19497.

36. Chowdhury S, Jarecki BW, Chanda B. A molecular framework for temperature-dependent gating of ion channels. Cell 2014;158:1148-1158.

37. Gardill BR, Rivera-Acevedo RE, Tung CC, et al. The voltage-gated sodium channel EF-hands form an interaction with the III-IV linker that is disturbed by disease-causing mutations. Sci Rep 2018;8:4483.

38. Abdelsayed M, Peters CH, Ruben PC. Differential thermosensitivity in mixed syndrome cardiac sodium channel mutants. J Physiol 2015;593:4201-4223.

39. Lau K, Van Petegem F. Crystal structures of wild type and disease mutant forms of the ryanodine receptor SPRY2 domain. Nat Commun 2014;5:5397.
40. Yuchi Z, Lau K, Van Petegem F. Disease mutations in the ryanodine receptor central region: Crystal structures of a phosphorylation hot spot domain. Structure 2012;20:1201-1211.

41. Antzelevitch C, Patocskai B. Brugada syndrome: Clinical, genetic, molecular, cellular, and ionic aspects. Curr Probl Cardiol 2016;41:7-57.

42. Amin AS, Meregalli PG, Bardai A, et al. Fever increases the risk for cardiac arrest in the Brugada syndrome. Ann Intern Med 2008;149:216-218.

43. Bennett PB, Yazawa K, Makita N, et al. Molecular mechanism for an inherited cardiac arrhythmia. Nature 1995; 376:683-685.

44. Wan X, Chen S, Sadeghpour A, et al. Accelerated inactivation in a mutant $\mathrm{Na}+$ channel associated with idiopathic ventricular fibrillation. Am J Physiol Heart Circ Physiol 2001;280:H354-H360.

45. Shivkumar K, Ajijola OA, Anand I, et al. Clinical neurocardiology defining the value of neuroscience-based cardiovascular therapeutics. J Physiol 2016;594:3911-3954.

46. Cortada E, Brugada R, Verges M. Trafficking and function of the voltage-gated sodium channel beta2 subunit. Biomolecules 2019;9:604.

47. Dhar Malhotra J, Chen C, Rivolta I, et al. Characterization of sodium channel alpha- and beta-subunits in rat and mouse cardiac myocytes. Circulation 2001;103:1303-1310.

Address correspondence to: Filip Van Petegem, $M S c$, PhD

Department of Biochemistry and Molecular Biology University of British Columbia Vancouver Canada

E-mail: filip.vanpetegem@gmail.com

Frank Bosmans, MPharm, PhD Ghent University

Corneel Heymanslaan 10, Building B, entrance 36 Ghent 9000 Belgium

E-mail: frank.bosmans@ugent.be 